\title{
openheart Bioresorbable vascular scaffold: promises and the fallen child-as-king?
}

\author{
Stephane Cook, ${ }^{1}$ Pascal Meier ${ }^{2,3}$
}

To cite: Cook S, Meier P. Bioresorbable vascular scaffold: promises and the fallen child-as-king?. Open Heart 2016;3:e000527. doi:10.1136/openhrt-2016000527

Accepted 14 September 2016

\section{SLinked}

- http://dx.doi.org/10 1136/openhrt-2016-000462

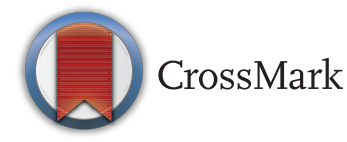

\footnotetext{
${ }^{1}$ Department of Cardiology, Hospital \& University Fribourg, Fribourg, Switzerland

${ }^{2}$ Department of Cardiology, University Hospital Geneva, Geneva, Switzerland

${ }^{3}$ Institute of Cardiovascular Science, University College London UCL, London, UK
}

Correspondence to Stéphane Cook; stephane.cook@unifr.ch

\section{THE BIORESORBABLE VASCULAR SCAFFOLDS 'BVS'}

The main limitation of percutaneous coronary intervention compared to open-heart surgery is the insertion of a foreign body (usually a stent) inside the coronary artery. This is associated with foreign body inflammation that triggers restenosis, neoatherosclerosis and late-occurring stent thrombosis. As such, BVS were considered as a possible solution as early as the late $60 \mathrm{~s}$ by Dotter with preclinical work, ${ }^{1}$ and then with the first human study by Higaki and Tamai ${ }^{2}$ in the late 90s. In these two preliminary experiments, device materials had weak radial strength and came with the risk of scaffold thrombosis (ScT). In addition, long-term preliminary studies of the Higaki-Tamai stent showed pathological remodelling of the artery during the first 3 years. Based on these studies, this early concept was soon abandoned. In 2004 following concerns of late drug-eluting stent (DES) thrombosis and its association with hypersensitivity reaction to permanent polymer, we saw a renewed interest in bioresorbable polymers. First, durable polymers on metallic DES were progressively swapped for lower dose, bioresorbable polymers. Second, a modified version of BVS that combines a novel stent design, a semicrystalline poly L-lactic acid (PLLA) backbone and a coating with everolimus was considered. This seminal work resulted in the first drug-eluting BVS, and subsequently in its first human implantation.

\section{BVS AND ITS PROMISES}

The announcement of the first clinical BVS implantation by Ormiston ${ }^{3}$ generated optimism during the great DES depression of 2006: BVS could potentially eradicate long-term adverse events (restenosis, late stent thrombosis and the newly described neoatherosclerosis) but could also result in possible coronary restoration with physiological vasomotion. Early studies with intravascular imaging were encouraging: early healing (capping) and the foundation of a new concept: the golden tube with positive vessel remodelling, disappearance of atherosclerotic plaque and progressive lumen enlargement. The child-as-king was born! In indirect comparisons, BVS was considered as good as the gold standard, everolimus-eluting metallic stents (EES) during the early clinical follow-up (7-34 months), after which, BVS appeared to perform better than EES. Although the first implantation was performed soon after its development thereafter, there was then a prolonged period of clinical research in highly selected patient populations and full commercial launch was only effective in late 2012. This resulted in an extension of usage to more complex lesions and patient populations and allowed comparison of the early promise from pioneering clinical research to real world contemporary practice. So, what have we learnt so far?

\section{BVS IS FEASIBLE}

The first promise was easily held: although its deliverability remains slightly below the current DES standard, BVS can be implanted in virtually all types of lesions. However, very accurate sizing with qualitative comparative analysis or intravascular ultrasound imaging (or optical coherence tomography (OCT)) is necessary to minimise malapposition, or the rupture of the scaffold backbone. We also learnt that edge dissections could originate from the manufacturing process of the scaffold (laser cutting without polishing).

\section{BVS IS EFFICIENT}

This promise remains a topic of debate. The very first clinical trial results with direct comparison between BVS and DES were available at TCT 2014 (over 10 years from first clinical implant), with the presentation of the EverBio-2 $^{4}$ and ABSORB-II. ${ }^{5}$ Key findings were as follows: no difference between devices on clinical end points with a reduced cumulative duration of secondary angina 
pectoris with BVS in ABSORB-II; but an increased in-segment late-lumen loss-a surrogate marker of efficacy - with BVS in EverBio-2. The ABSORB III trial subsequently confirmed these results. Nevertheless, the power of these studies taken individually remains insufficient to conclude about individual clinical end points, especially device thrombosis. Furthermore, the study designs with generous thresholds chosen for noninferiority have favoured BVS (such as a wide $\delta$ margin of $4.5 \%$ in ABSORB III $^{6}{ }^{7}$ ).

\section{SCT AND THE FALLEN (CHILD-AS-) KING}

A firestorm arose in early 2014 from the observational GHOST-EU registry, ${ }^{6}{ }^{7}$ which showed an increased rate of ScT in unselected patients, with an incidence of $>2 \%$ at 6 months. These results were confirmed by other studies. Intravascular imaging studies at time of ScT identified similar causative factors: scaffold malexpansion, dissection, malapposition and insufficient antiplatelet therapy. ${ }^{8}$ Subsequently it was shown that, careful patient and lesion selection with a dedicated implantation technique significantly reduces the risk of ScT as demonstrated by Puricel et al. ${ }^{9}$ Nevertheless and as already experienced by Dotter or Higaki and Tamai, BVS thrombogenicity remains higher than with DES. This was nicely illustrated by Joner ${ }^{10}$ using an arteriovenous shunt model, this group demonstrated how accentuated fibrin deposition forms in the vicinity of the struts with the formation of a 'chronic thrombus'. This demonstration breaks the myth of capping. Indeed, in light of these results, it is reasonable to think that the capping visible at OCT does not represent healing but an organised 'chronic' thrombus. Furthermore, from late ScT, we learnt some further points: (A) BVS is associated with peristrut low intensity areas when studies with OCT analyses are performed after 3 months. This may indicate parietal oedema induced by chronic inflammation or polymer degradation itself (via the Krebs cycle). This is associated with strut discontinuities, sagging, recoil and occasionally complete collapse of the scaffold within the coronary lumen. ${ }^{11}$ (B) Obstructive neoatherosclerosis might be found in BVS. (C) The duration for complete degradation remains unknown, particularly in diseased segments but takes more than initially considered, possibly 3-4 years. (D) Positive remodelling of the artery is not necessarily positive for the patient, since it may be associated with coronary aneurysm and ScT.

\section{BVS AND CLINICAL EVIDENCE}

From the DES saga, we should yet remember that stent (or scaffold) thrombosis has little impact on clinical outcome. ${ }^{12}$ Therefore, it is time to turn back to clinical evidence. Accordingly and in this edition of the journal, Farag $e t a l^{13}$ present a meta-analysis of the first trials on BVS. This is the fifth meta-analysis on this subject. ${ }^{14-17}$ This meta-analysis differs from the first four analyses by separating analysis of the six randomised controlled trials from analysis of six clinical registries. The authors should be congratulated for their work. Using powerful statistical tools, they show convincing results that are close to previous meta-analyses with a significantly increased risk of myocardial infarction and ScT rates with BVS. This new meta-analysis also demonstrates that these differences seen in RCTs, disappeared in registries. This is a new finding and may provide some reassurance to patients receiving BVS. The reasons of the apparent discrepancy are beyond the scope of the current analysis. However, there are some plausible explanations: one possibility advanced by the authors could be the use of a dedicated implantation technique in the registry arm (2× more intravascular imaging use, higher postdilation balloon size and pressure in registries compared to RCT). But such interpretation is open to possible biases and type 2 errors. Finally, what these studies omit to underscore is that the typical patient with BVS is on average 6 years younger than the typical DES patient; with a higher proportion of men, less diabetes, less acute coronary syndromes and less treated lesions.

\section{BVS AND THE FUTURE}

Taking all items together, the question is whether we took a step forwards or backwards with BVS as in 2006 with the ESC DES Firestorm. ${ }^{18}$ This is of particular interest given that beside BVS the latest DES platforms have significantly evolved, combining low-dose of bioresorbable polymer with low-dose antiproliferative drugs on thinlayered metal backbones. So, it is urgent to .... wait! Given that the potential benefit of BVS should be seen after 3 years (once the scaffold has resorbed), for now we need to wait for these long-term results. In the interim physicians should carefully weigh the individual risks (eg, prolonged dual antiplatelet therapy) versus the potential benefits of BVS on an individual patient basis and consider it primarily in simple non-calcified lesions or longer lesions (possible vascular restoration therapy), with thorough lesion preparation and using a dedicated implantation technique to maximise the chances of success.

Competing interests None declared.

Provenance and peer review Commissioned; internally peer reviewed.

Open Access This is an Open Access article distributed in accordance with the Creative Commons Attribution Non Commercial (CC BY-NC 4.0) license, which permits others to distribute, remix, adapt, build upon this work noncommercially, and license their derivative works on different terms, provided the original work is properly cited and the use is non-commercial. See: http:// creativecommons.org/licenses/by-nc/4.0/

\section{REFERENCES}

1. Dotter CT. Transluminally-placed coil spring endarterial tube grafts. Long-term patency in canine popliteal artery. Invest Radiol 1969;4:329-32.

2. Tamai $\mathrm{H}$, Igaki $\mathrm{K}$, Kyo $\mathrm{E}$, et al. Initial and 6-month results of biodegradable poly-l-lactic acid coronary stents in humans. Circulation 2000;102:399-404.

3. Ormiston JA, Serruys PW, Regar E, et al. A bioabsorbable everolimus-eluting coronary stent system for patients with single de-novo coronary artery lesions (ABSORB): a prospective open-label trial. Lancet 2008;371:899-907. 
4. Puricel S, Arroyo D, Corpataux N, et al. Comparison of everolimusand biolimus-eluting coronary stents with everolimus-eluting bioresorbable vascular scaffolds. J Am Coll Cardiol 2015;65:791-801.

5. Serruys PW, Chevalier B, Dudek D, et al. A bioresorbable everolimus-eluting scaffold versus a metallic everolimus-eluting stent for ischaemic heart disease caused by de-novo native coronary artery lesions (ABSORB II): an interim 1-year analysis of clinical and procedural secondary outcomes from a randomised controlled trial. Lancet 2015;385:43-54.

6. Ellis SG, Kereiakes DJ, Metzger DC, et al. Everolimus-eluting bioresorbable scaffolds for coronary artery disease. $N$ Engl J Med 2015;373:1905-15.

7. Capodanno D, Gori T, Nef $\mathrm{H}$, et al. Percutaneous coronary intervention with everolimus-eluting bioresorbable vascular scaffolds in routine clinical practice: early and midterm outcomes from the European multicentre GHOST-EU registry. Eurolntervention 2015;10:1144-53.

8. Cuculi F, Puricel S, Jamshidi P, et al. Optical coherence tomography findings in bioresorbable vascular scaffolds thrombosis. Circ Cardiovasc Interv 2015;8:e002518.

9. Puricel S, Cuculi F, Weissner M, et al. Bioresorbable coronary scaffold thrombosis: multicenter comprehensive analysis of clinical presentation, mechanisms, and predictors. J Am Coll Cardiol 2016:67:921-31.

10. Koppara T, Cheng Q, Yahagi K, et al. Thrombogenicity and early vascular healing response in metallic biodegradable polymer-based and fully bioabsorbable drug-eluting stents. Circ Cardiovasc Interv 2015;8:e002427.
11. Arroyo D, Cook S, Puricel S. Mechanisms of late and very late bioresorbable vascular scaffold thrombosis: is it only about flow? J Am Coll Cardiol 2016;67:1259-60.

12. Stone GW, Ellis SG, Colombo A, et al. Offsetting impact of thrombosis and restenosis on the occurrence of death and myocardial infarction after paclitaxel-eluting and bare metal stent implantation. Circulation 2007:115:2842-7.

13. Farag M, Spinthakis N, Gorog DA, et al. Use of bioresorbable vascular scaffold: a meta-analysis of patients with coronary artery disease. Open Heart 2016;3:e000462.

14. Cassese S, Byrne RA, Ndrepepa G, et al. Everolimus-eluting bioresorbable vascular scaffolds versus everolimus-eluting metallic stents: a meta-analysis of randomised controlled trials. Lancet 2016;387:537-44

15. Stone GW, Gao R, Kimura T, et al. 1-year outcomes with the Absorb bioresorbable scaffold in patients with coronary artery disease: a patient-level, pooled meta-analysis. Lancet 2016;387:1277-89.

16. Lipinski MJ, Escarcega RO, Baker NC, et al. Scaffold thrombosis after percutaneous coronary intervention with ABSORB Bioresorbable vascular scaffold: a systematic review and meta-analysis. JACC Cardiovasc Interv 2016;9:12-24.

17. Kang SH, Chae IH, Park JJ, et al. Stent thrombosis with drug-eluting stents and bioresorbable scaffolds: evidence from a Network meta-analysis of 147 trials. JACC Cardiovasc Interv 2016;9:1203-12.

18. Arroyo D, Cook S, Puricel S. Bioresorbable vascular scaffolds-time to vanish? J Thorac Dis 2016;8:E431-6. 